\title{
Saúde, promoção da saúde e agentes multiplicadores: concepções de profissionais de saúde e de educação do município do Rio de Janeiro
}

\author{
Health, health promotion and multiplying agents: concepts of health and education \\ professionals in the city of Rio de Janeiro, Brazil
}

\author{
Luciana M. C. Castro' \\ Sheila Rotenberg ${ }^{2}$ \\ Silvia A. Gugelmin ${ }^{3}$ \\ Thais Salema N. de Souza ${ }^{4}$ \\ Luciana A. Maldonado' \\ Maria Fátima G. Menezes' \\ Mariângela C. Valente'
}

\footnotetext{
1 Instituto de Nutrição, Universidade do Estado do Rio de Janeiro. Rio de Janeiro, RJ, Brasil.

${ }^{2}$ Faculdade de Nutrição, Departamento de Nutrição Social. Universidade Federal Fluminense. Niterói, RJ, Brasil.

${ }^{3}$ Instituto de Saúde Coletiva, Universidade Federal de Mato Grosso. Cuiabá, MT, Brasil

${ }^{4}$ Escola de Nutrição, Departamento de Nutrição em Saúde Pública. Universidade Federal do Estado do Rio de Janeiro. Rio de Janeiro, RJ, Brasil.

Correspondência / Correspondence Luciana M. C. Castro

Instituto de Nutrição, Universidade do Estado do Rio de Janeiro

Rua São Francisco Xavier, 524, 12 andar, Bloco D, sala 12.007

Rio de Janeiro, RJ, Brasil

E-mail: lucastro@veri.br
}

\section{Resumo}

Os profissionais das áreas da saúde e educação têm papel importante no contexto da promoção da saúde. Este trabalho objetiva compreender suas concepções sobre saúde, promoção da saúde e agentes multiplicadores, uma vez que a maneira como pensam pode direcionar as práticas profissionais. Foram realizados sete grupos focais, sendo quatro com profissionais da educação (28 participantes) e três com profissionais da saúde (27 participantes). Para a análise, buscou-se interpretar e compreender as falas, identificando-se as categorias temáticas. Observou-se que os profissionais de saúde têm o conceito de saúde compreendido como resultante das condições de vida. Os educadores discutem suas dificuldades cotidianas para ter saúde, ressaltando a dupla jornada de trabalho. Em relação à promoção de saúde, os profissionais de saúde destacam seu papel como agentes de transformação. Os profissionais de educação apontam o acesso à informação como possibilidade de melhoria da qualidade de vida. Os resultados apontam para a necessidade de maior aproximação entre os campos, possibilitando um redirecionamento da prática com vistas à realização de ações intersetoriais de promoção de saúde e qualidade de vida. Este é um processo que demanda investimentos institucionais em educação permanente, na organização e na problematização do processo de trabalho.

Palavras-chave: Saúde. Promoção da Saúde. Profissionais da Saúde. Profissionais da Educação. 


\section{Abstract}

Health and education professionals play a very important role in the context of health promotion. This paper aims at understanding their concepts about health, health promotion and multiplying agents, as far as the way they think can direct their professional practices. Seven focus groups were set, as follows: four with education professionals (total of 28 participants) and three groups with health professionals (total of 27 participants). In order to analyze the material, we sought to interpret and comprehend their talks, identifying the thematic categories. It was observed that health professionals have a concept of health as a result of life conditions. Education professionals discuss their daily difficulties to achieve health, emphasizing their work in double shifts. In relation to health promotion, health professionals emphasize their role as transformation agents. The education professionals point the access to information as a possibility of improving the quality of life. The results point out to the need of greater connection between both fields - health and education, making it possible to redirect practice, aiming at the achievement of inter-sectoral actions of health promotion and quality of life. This process demands institutional investment in continuing education, in organization, as well as focusing on the discussion on the work process.

Key words: Health. Health Promotion. Health Professionals. Education Professionals.

\section{Introdução}

A promoção de saúde é uma estratégia presente nas agendas da saúde e da educação pública do país, devendo ser componente fundamental das ações intersetoriais dirigidas para a garantia do direito humano à alimentação, para a Segurança Alimentar e Nutricional e melhoria da qualidade de vida. As estratégias utilizadas para a promoção da saúde devem envolver a coletividade, a fim de que ela participe no controle do processo saúde-doença e atue na melhoria de sua qualidade de vida. Segundo o Ministério da Saúde, ${ }^{1}$ a promoção da saúde é

[...] uma estratégia de articulação transversal na qual se confere visibilidade aos fatores que colocam a saúde da população em risco e às diferenças entre necessidades, territórios e culturas presentes no nosso país, visando à criação de mecanismos que reduzam as situações de vulnerabilidade, defendam radicalmente a equidade e incorporem a participação e o controle sociais na gestão das políticas públicas. 
A apropriação dos processos da promoção da saúde pela população requer dos profissionais maior abertura para o diálogo e a aquisição de conhecimentos relativos à dinâmica do "ensinaraprender", de modo crítico, reflexivo e transformador. Antes disso, para que as práticas e conhecimentos conjugados estabeleçam uma nova forma de agir, é importante que os profissionais entendam a coexistência de diferentes saberes e estabeleçam aproximações, demonstrando interesse por suas vivências. ${ }^{2} \mathrm{O}$ papel dos profissionais como agentes multiplicadores implica fortalecer o poder técnico e político das comunidades (empowerment) no reconhecimento de prioridades, na tomada de decisões e na construção coletiva de estratégias para a melhoria das condições de saúde e de vida. ${ }^{3,4}$

Apesar da existência de vários conceitos de saúde presentes em discursos técnico-científicos ou do senso comum, poucos são os estudos que se dedicam a explorar o conceito do ponto de vista epistemológico. ${ }^{5}$ Entendemos que cada indivíduo tem para si a própria concepção de saúde definida por sua formação e inserção no mundo. ${ }^{6}$ No caso de profissionais de saúde e de educação, esta definição pode ter papel importante em sua prática, direcionando suas maneiras de cuidar e se colocar como agente de transformação no contexto da promoção da saúde. Como salientam Brito \& Athayde, ${ }^{7}$ mesmo na atividade mais simples, no ato de sua execução, os trabalhadores são desafiados a fazer escolhas, decidir caminhos - enfim, a renormatizar em meio às prescrições e seus próprios referenciais de vida. Conhecer estes modos de ver a saúde pode contribuir para o planejamento de programas, projetos e ações que promovam a saúde, seja no contexto da escola, seja nas comunidades.

Com base no contexto abordado, consideramos relevante identificar as concepções de profissionais sobre o que é saúde, promoção da saúde, e o que compreendem por agentes multiplicadores. Essa discussão pode ajudar os participantes a compreender o significado e as dimensões estratégicas da prática educativa no ato de cuidar, possibilitando a valorização de propostas de Educação em Saúde. Todas estas são ideias compartilhadas com os sujeitos da pesquisa e que foram dimensionadas no campo das práticas, de modo a qualificar as ações educativas na área da promoção da alimentação saudável e adequada.

\section{Metodologia}

Este estudo é parte integrante de uma pesquisa proposta pelo Instituto de Nutrição Annes Dias (INAD), órgão da Secretaria Municial de Saúde do Rio de Janeiro (SMS-Rio) e Instituto de Nutrição da Universidade do Estado do Rio de Janeiro (UERJ), que visava desenvolver um método para formação de multiplicadores das áreas de saúde e educação para a promoção da alimentação saudável, utilizando a culinária como eixo estruturante. ${ }^{4}$ 
Como primeira atividade, foi utilizada a técnica do grupo focal (GF) para apreender a concepção dos participantes sobre os conceitos de saúde, promoção da saúde e agentes multiplicadores, que seriam utilizados durante o processo de formação a ser implementado em momento posterior da pesquisa.

Este artigo apresenta os resultados da análise das discussões realizadas nos grupos focais. $\mathrm{O}$ GF é uma ferramenta da metodologia qualitativa, a qual objetiva a compreensão aprofundada de um tema ou questão dentro de um grupo determinado, por meio da análise da linguagem verbal e não verbal da população de estudo. ${ }^{8,9}$ Nesse tipo de estudo, a discussão é conduzida numa forma de diálogo conjunto entre os participantes sobre um tema específico. Essa flexibilidade permite a superação das dificuldades dos contatos breves e dos questionários fechados, os quais não estão sensíveis ao recebimento de informações não previstas. ${ }^{9,10}$

Em junho de 2006, foram realizados sete grupos focais, sendo quatro com profissionais da educação, totalizando 28 participantes representantes das diversas coordenadorias regionais do município do Rio de Janeiro; e três grupos com profissionais da saúde, com um total de 27 participantes, envolvendo membros das equipes da Estratégia Saúde da Família. Esses profissionais foram identificados por meio de contato com informantes privilegiados das áreas de saúde e educação, que desenvolviam atividades cotidianas com o tema de interesse. Os grupos foram desenvolvidos em local externo ao ambiente de trabalho dos participantes, sendo conduzidos por coordenadores e auxiliados por um observador, todos da equipe do projeto, e debateram livremente sobre as questões norteadoras: o que vocês entendem por saúde? O que vocês entendem por promoção de saúde? E o que vocês entendem por agentes multiplicadores?

As discussões foram gravadas com a anuência dos participantes e, posteriormente, foram feitas as transcrições. Com base no método de análise temática, buscou-se interpretar e compreender as falas, o contexto de sua produção e as contradições e conflitos inerentes aos processos sociais, identificando as categorias temáticas. ${ }^{11-13}$

Os participantes, após estarem cientes das etapas do projeto, assinaram um termo de consentimento livre e esclarecido para participação no estudo. O projeto foi submetido ao Comitê de Ética em Pesquisa da Secretaria Municipal de Saúde e Defesa Civil do Rio de Janeiro.

O perfil do grupo participante está assim descrito: 1) Profissionais da rede básica de saúde (PS): membros de equipes de Saúde da Família e dos Grupos de Apoio Técnico (GAT), entre médicos, assistentes sociais, enfermeiros, massoterapeutas, agentes comunitários de saúde e nutricionistas; representante do nível central da SMS-Rio : Estratégia de Saúde da Família (ESF), Assessoria de Promoção da Saúde e da Gerência de Saúde Escolar. 2) Profissionais da educação (PE): coordenadores pedagógicos, professores do primeiro segmento do ensino fundamental ou pré-escola, professores de segundo segmento, professores atuantes no projeto Salas de Leitura, 
coordenadores e articuladores de creche, representantes das Coordenadorias Regionais de Educação (CRE) e representante do nível central da Secretaria Municipal de Educação (SME): Divisão de Alimentação Escolar da e gerente de saúde escolar.

\section{Resultados e discussão}

\section{Conceito de saúde}

Ao analisar as falas, identificamos que os profissionais de saúde e de educação abordam de maneira diferenciada o termo "saúde". Essa definição, como já mencionado, apresenta diversos significados, não sendo estranha a polissemia de interpretações entre os entrevistados desse estudo. Foram identificadas três categorias temáticas para a definição de saúde, quais sejam: 1) idealização da saúde; 2) saúde e condições de vida; e 3) organização da vida contemporânea: bem individual e autocuidado.

Alguns participantes da área da saúde se aproximaram do conceito da Organização Mundial da Saúde (OMS), que entende saúde como um estado de completo bem-estar físico e mental, campo idealizado e muitas vezes distante do cotidiano do indivíduo. No entanto, outros tentam se distanciar dessa definição, incorporando aspectos direcionados a qualidade de vida, felicidade, otimismo, esperança (PS14, PS4) e seus determinantes, como privações e miséria, acesso e direito à saúde, caracterizado como o acesso a bens, educação, cultura, emprego e lazer (PS4, PS6, PS11). Esta definição se aproxima da realidade vivida, contextualizada no ambiente e nas relações sociais Os profissionais movimentam-se para pensar a saúde em seus aspectos positivos e não mais como ausência de doença, tal qual mencionado no Relatório final da VIII Conferência Nacional de Saúde. ${ }^{14}$

A gente não pode entender saúde como uma ausência de doença, é muito mais do que isso. Mas também não é esse equilíbrio físico, mental, social. Isso é uma coisa muito, muito longe. [...] É você estar se sentindo bem, mesmo até que você tenha uma doença qualquer, [...] de estar fazendo aquilo que eu me propus a fazer na vida; está relacionado mesmo à direção que você dá a sua vida, às escolhas, às tomadas de decisão (PS1).

Destaca-se que os representantes da área da saúde compunham equipes da ESF e, por estarem mais próximos da população, podem ter compreensão mais ampla das adversidades e possibilidades vivenciadas no cotidiano dos territórios. Assim, a saúde deixa de ser compreendida como uma simples ausência de doenças e passa a ser concebida como resultante das condições de vida de uma população, necessitando, para sua manutenção, de políticas públicas intersetoriais eficientes. ${ }^{14,15}$ 
Uma questão recorrente nas falas dos profissionais das duas áreas diz respeito a saúde e condições de vida em um contexto de violência urbana.*

[...] o conceito de ter saúde que nós temos aprendido é estar bem, é ter uma boa qualidade de vida, é poder ter liberdade de ir e vir, é poder ter um emprego, ter uma família. [...] Eu tenho observado a dificuldade dessa população [...], pra eles é muito difícil porque eles vivem no meio de guerra,... é tiroteio, é o cara traficando na porta da casa dele. Então, como eu vou explicar pra ele o que é saúde? [...] como ele vai estar bem se a comunidade está toda mal? (PS7).

Como você pode estar saudável numa cidade convivendo com a violência do jeito que a gente está?... O que acontece até em outras partes do mundo nos afeta aqui. Você não pode ser totalmente saudável vivendo num lugar onde as pessoas... os nossos alunos, que moram na favela e que convivem com os tiroteios. (PE4).

Em 2002, a Organização Mundial da Saúde (OMS) $)^{16}$ afirmou: "em todo o mundo a violência vem se afirmando como um dos mais graves problemas sociais e de saúde pública”. Em 2008, a Pesquisa Nacional de Amostra Domiciliar (PNAD) mostrou que, dentre a população residente no Brasil (190,0 milhões), cerca de 2,0\% (3,7 milhões) sofreram algum tipo de violência; e entre as pessoas vitimadas e que deixaram de realizar suas atividades habituais, 660 mil (53\%) precisaram recorrer a algum serviço como hospital, pronto-socorro ou ambulatório. ${ }^{17}$ Assim, a violência contemporânea se torna uma questão a ser priorizada pelas agendas, tanto da saúde como da educação, pois vem trazendo novos desafios ao cotidiano dos trabalhadores. ${ }^{18}$

Outra categoria temática identificada é a saúde como bem individual. As falas dos profissionais de educação expressam o conceito, relacionando-o às escolhas pessoais que poderão determinar mais ou menos saúde (PE1), autocuidado e equilíbrio.

Eu acho que a questão vem do equilíbrio. Eu acho que estar saudável é você ter consciência de que você precisa fazer coisas boas, um minuto hoje, um tempinho do dia pra você é muito importante. Te faz um bem quando você consegue ir a um cabeleireiro, parece uma coisa fútil alguém lavar a tua cabeça, seus cabelos, suas unhas... (PE5).

Destacamos que os hábitos ou "estilos de vida" expressos por práticas cotidianas não são iguais para todos nem puramente atitudes individuais conscientes, isoladas e imutáveis. ${ }^{19,20}$ Segundo Nogueira, ${ }^{21}$ ao sentir, pensar e experimentar a própria saúde, compreende-se a si mesmo como

* Esta pesquisa foi realizada antes da instalação das Unidades de Polícia Pacificadora (UPPs), na cidade do Rio de Janeiro. 
estando num jogo existencial, que inclui o tempo, a história e o ser e estar no mundo. Ao fazer uma (auto)reflexão, pode-se descortinar e abrir possibilidades para atuar no âmbito da sociedade.

Desta forma, os temas trabalhados no grupo focal e discutidos à luz da "problematização" puderam propiciar segundo Bucher-Marluschke, ${ }^{22}$ uma releitura da realidade. Este processo de ressignificação é gerador de consciência crítica onde os participantes reconhecem que a realidade é mutável. Possibilita ao sujeito que aprende refletir sobre sua realidade, buscar soluções e neste processo construir um conhecimento significativo. Para a mesma autora, a construção do conhecimento implica uma interação comunicacional, onde os sujeitos de saberes diferentes se relacionam a partir de interesses comuns.

Diferentemente dos profissionais de saúde, os de educação discutem a saúde vivenciada por eles, relacionada a seu cotidiano e a suas relações interpessoais, enfatizando a difícil incorporação do conceito no dia a dia, à falta de tempo que se defronta com uma saúde idealizada e difícil de atingir, em especial numa grande metrópole.

Não adianta você ter uma boa alimentação, mas viver estressado com problemas no trabalho, problemas em casa, né? O filho, não consegue ver, ta com saudade. Não dá certo, a gente fica doente. (PE14).

É complicado porque a gente, por exemplo, leva uma hora pra chegar no trabalho, leva uma hora pra voltar do trabalho, tem que cumprir uma carga horária de 10, 11 horas porque tem duas matrículas, FG [função gratificada]. Onde você arruma força pra chegar em casa e ser mãe e ser dona de casa e tudo? (PE6)

E você sabe tudo que você precisa fazer para ter [saúde], mas que chegam determinadas situações que você não consegue... Chega um momento na nossa vida que, nessa vida enlouquecida que a gente leva que realmente você pára e pensa: Caramba! Eu to doente porque eu não consigo realizar tudo que é necessário pra eu ser saudável! (PE9).

O gatilho da gente só aciona quando a gente empaca mesmo. [...] Porque enquanto ainda dá pra ir levando, você vai levando, você empurra... (PE14).

A partir de meados do século XX, estabeleceu-se uma nova composição social, marcada pela urbanização, industrialização e expansão das atividades educacionais que alteraram os modos de produção e as relações de trabalho. As mulheres foram para o mundo público, da política, do mercado de trabalho e da educação, tentando romper com a dicotomia entre público e privado, papel social masculino e feminino. ${ }^{23}$ A entrada da mulher no mercado de trabalho formal ocasionou a dupla ou tripla jornada de trabalho ${ }^{24,25} \mathrm{e}$, segundo Oliveira, ${ }^{26}$ " os sintomas psicofísicos são semelhantes nos homens e nas mulheres, mas os impactos sobre a saúde são diferentes devido à dupla ou tripla jornada”, dentre outros aspectos. 
Após estas análises, pode-se perceber que a primeira questão proposta - "o que vocês entendem por saúde?” - revela que os profissionais de saúde têm este conceito relacionado à sua prática diária, sua observação sobre o meio e sobre como esse meio interfere na vida das pessoas, utilizando conhecimento teórico sobre o assunto. Por outro lado, os profissionais de educação discutem suas dificuldades cotidianas para ter saúde. Este tema aparece um pouco distanciado de sua prática profissional.

\section{Promoção da saúde}

Em relação à promoção de saúde foram identificadas três categorias temáticas: como possibilidade de construção e transformação individual e coletiva; como práticas coercitivas e impositivas; e acesso à informação

Em relação aos profissionais de saúde as discussões apontam para a abordagem sobre o papel do profissional de saúde como agente de transformação, numa tentativa de incorporar a dialogicidade, de cuidar do outro, o que requer, neste caso, a aceitação do outro como sujeito e não como objeto de intervenção ${ }^{27}$

Eu acho que os profissionais de saúde, nós temos uma responsabilidade muito grande em relação a isto, de proteção não é? Acho que isso já começa dentro da Unidade. Dentro do próprio consultório. O profissional está tendo aquela visão integral do indivíduo. (PS6).

[...] você tem que apoiar, ajudar, mostrar aquela pessoa que hoje está ruim, mas amanhã vai ser diferente. (PS13).

[...] um modo de ajudar na saúde dessas pessoas, porque você vai orientar, você vai conversar, você puxa pra um grupo pra eles ficarem junto com os outros e eles já vão vendo a diferença, vão mudando aos poucos... e eles já vão passando pra outras pessoas, inclusive eles vão ser também multiplicadores porque cada um vai e já convida o outro pro próximo encontro. (PS3).

Enfatizam também a cidadania e construção partilhada.

Passa muito pela cidadania também. Eu acho que promoção de saúde tem que estar junto com promoção de cidadania... (PS8).

Então acho que isso não é promoção. Você falar o que tem que ser feito sem estar partilhando... Indo... Percorrendo o caminho para que aquela situação se alterne. [...] Saia de um ponto x para o outro que esteja mais próximo ao que a gente considera como saúde... Estar junto é fundamental. (PS12). 
Abordam também a promoção da saúde como transformação individual e coletiva.

Quando eu penso em promoção, a primeira palavra que me vem é de construção [...] construção e transformação [...] e [...] transformar sim, tanto no ambiente externo, mas também nos ambientes internos, quer dizer, tanto no individual como no coletivo. (PS10).

Ainda identificamos, no entanto, que parte dos profissionais expressa práticas tradicionais, coercitivas e impositivas. A relação também é opressora e subjulgante, utilizando artifícios calcados na solidariedade para se manter em posição de domínio. ${ }^{28}$

Aquele trabalho massificante. Sabe... Você ficar ali não é? Batendo na cabeça. Lavagem cerebral para as crianças quando forem mães entenderem aquilo e começar inserir aquilo na alimentação. (PS2).

Então, promoção de saúde numa realidade do agente de saúde. A gente tem que chegar no extremo para poder conseguir que eles mudem alguma coisa. Porque só chegar e falar "Ah! Você tem que beber água filtrada". Não entra na cabeça. (PS4).

Pois, eu escandalizei [risos]. Tendo um monte de ferida no pé. Tudo ruim... Um monte de fotos - "Olha! Seu pé vai ficar assim". Tem hora que a gente não pode falar para ele o que ele quer ouvir falar. Tem que falar o que ele precisa! - "Seu pé vai cair, Sr. Antônio. Vai ficar assim mesmo... O senhor não tá tomando o remédio... (PS6).

Essas falas expressam, ainda, a abordagem de culpabilização do indivíduo, que almeja apenas a mudança no "comportamento de risco", portanto limitada, pois acredita que o indivíduo é o único responsável por sua saúde ou doença, sem considerar as inúmeras questões envolvidas nesse processo. $^{29}$

O modelo hegemônico de educação e de saúde foi, durante muitos anos, vertical, marcado pelo autoritarismo, onde predominavam as imposições dos técnicos que utilizavam as práticas educativas como estratégia de controle social, adaptando os indivíduos à ordem vigente. A crítica ao modelo tradicional de ensino, a ampliação do conceito de saúde, a reforma sanitária e o fortalecimento dos movimentos sociais foram elementos que contribuíram para um novo paradigma do campo da educação em saúde, que culminou com a incorporação de metodologias participativas e dialógicas nas práticas educativas. ${ }^{30-32}$

Quando se ouvem os profissionais de educação, estes apontam que a promoção de saúde oferece acesso à informação, podendo gerar possibilidades de transformação, de melhoria da qualidade de vida, ressaltando que o assunto deve ser incluído no projeto político-pedagógico da escola. 
Mas até esse trabalho que a gente faz hoje em dia na creche, a gente tenta trabalhar a base pra que vocês, quando chegar mais na frente, vocês já tenham uma criança melhor preparada. Então, se a gente conseguir conscientizar essa família desde a educação infantil, da creche, ele vai modificar os hábitos, a gente vai estar promovendo a saúde. (PE13).

Estas intenções de promoção de saúde, tem que estar dentro de um projeto político pedagógico..., pra que todos numa mesma intenção trabalhem nessa questão, porque aí aquilo vai ficar tendo ali uma identidade, daquela unidade escolar, daquele espaço. (PE7).

As escolas, assim como os serviços de saúde, podem ser locais privilegiados de promoção da saúde, possibilitando tanto a ampliação do acesso à informação, favorecendo a compreensão da saúde como direito e responsabilidade individual e coletiva, bem como a construção de habilidades essenciais no cotidiano do cidadão - como autocuidado, senso crítico e capacidade decisória. ${ }^{33,34}$

No entanto, também permanece nas falas dos profissionais de educação um discurso tradicional de repasse e divulgação de informações.

Você promover às outras pessoas essa situação saudável. [...] Então, essa promoção é realmente você levar às outras pessoas a mesma... se você conhece, se você sabe que faz bem, é divulgar, passar pro outro. (PE5).

Eu acho que o que emperra essa promoção da saúde é a ignorância do nosso povo em não querer deixar ser ajudado. (PE8).

Como os profissionais de saúde, os de educação revelam também uma prática impositiva e contraditória.

Nós temos que ser transformadores, tem que virar o jogo, entendeu? Que ta tudo muito invertido... Você tem que criar novos hábitos, é a mudança em si”. (PE10)

Diversos autores apontam que a origem da educação em saúde no Brasil foi fortemente influenciada pelo desenvolvimento das doutrinas higienistas difundidas na Europa no século XIX. Vasconcelos ${ }^{35}$ salienta que, no início do século XX, o entendimento das autoridades sanitárias era de que "os técnicos detinham um saber científico que devia ser incorporado e aplicado pela população ignorante".

O campo da educação em saúde tem sido profundamente repensado e pode-se observar hoje uma valorização desse campo na determinação das políticas públicas de saúde e de educação no Brasil, ao lado de uma reação às práticas pedagógicas persuasivas, a transmissão verticalizada de 
conhecimentos e a negação da subjetividade nos processos educativos. Observa-se a preocupação de que a práxis educativa em saúde busque incentivar a constituição de sujeitos sociais reflexivos e capazes de reivindicar seus interesses. ${ }^{36}$

\section{Agentes multiplicadores}

Em relação à compreensão sobre a questão "o que entendem por agentes multiplicadores?”, foram identificadas duas categorias: informar para o convencimento; e compartilhar e socializar conhecimento com papel de protagonismo no processo de transformação

Os profissionais de saúde apontam que o multiplicador deve ser um agente de mobilização.

Mobilizar as lideranças comunitárias... pra conseguir que limpe essa praça, pra poder fazer uma atividade física nessa praça... Então, é a co-responsabilidade da comunidade. (PS5).

Passar informação. Multiplicar informação. Mas informação para todo mundo (PS4).

Ao mesmo tempo, que outros revelam que seu papel é divulgar informações através de um modelo tradicional de educação e saúde.

Então estas pessoas têm que passar rigorosamente por estas palestras. Tipo assim, educação continuada mesmo, né? (PS6).

Ressaltamos que o papel do profissional não consiste apenas em informar, orientar, mas problematizar os conhecimentos técnicos frente à realidade vivenciada. O desenvolvimento da reflexão crítica do educando possibilita que ele ocupe um lugar de sujeito da ação, considerando os limites e potencialidades das decisões individuais. ${ }^{37}$

Relatam também que a lógica de produtividade no processo de trabalho dos serviços de saúde dificulta a integralidade no atendimento e a promoção de saúde, e sugerem a formação de grupos educativos como estratégia de multiplicação.

A gente fica muito massacrado tendo que mandar números para a Secretaria... Porque se a gente não mandar número, a gente não recebe gratificação. (PS6).

Acho que um trabalho legal assim pra multiplicar bastante, seria um grupo, to fazendo um grupo que passa bastante coisa, e ai já vão dando uma idéia Grupo é muito importante assim, dá para passar. E ele já sai um passa pro filho, pro pai, pro vizinho, já fica uma coisa bem, sabe? (PS8). 
Quando indagados, os profissionais da educação também apresentaram a ideia do repasse de informação e de convencimento dos sujeitos da ação.

[O multiplicador deve] informar. (PE3).

Multiplicador não é só você passar a informação, mas é você convencer, entre aspas, o outro que aquela idéia não pare nele, pra que ele também, num outro grupo de ação dele, ele possa também estar divulgando e convencendo o outro a passar adiante. (PE12).

Por outro lado, outra idéia presente é a valorização da postura de compartilhar e socializar conhecimento e realizar as transformações.

[...] é você dividir com os outros aquilo que você assimilou (PE11).

Compreendem que o papel do multiplicador é compartilhar informações com os pares, colocar a teoria em prática e identificar-se como agentes de mudança, com um papel mais ativo, de protagonismo no processo.

E que a gente precisa ter sempre essa preocupação, de dividir com os outros tudo aquilo que a gente construiu né? (PE2).

[...] a gente passa por essa transformação pra poder, transformar também o outro, né... (PE1).

Assim, o profissional pode contribuir para a mudança. Como salienta Westphal, ${ }^{38}$ a população deve participar do processo através de seus grupos organizados e da sociedade civil, pois é ela que vive e sente os problemas no seu cotidiano. Se a discussão for aberta, as soluções serão mais reais e efetivas e a sociedade, protagonista da própria mudança.

\section{Conclusão}

Identificou-se assim que os profissionais de saúde, inseridos na ESF, têm o conceito de saúde relacionado à sua prática diária, sua observação sobre o meio e sobre como esse meio interfere na vida de todos. Por outro lado, os educadores, ao falarem de saúde, discutem mais suas dificuldades cotidianas para ter saúde, ressaltando a dupla jornada de trabalho.

Esse tema aparece um pouco distanciado de sua prática profissional. Os resultados apontam para a necessidade de maior aproximação entre os dois campos - saúde e educação -, assim como a incorporação da discussão sobre violência e do cuidado à saúde dos próprios profissionais, 
possibilitando um redirecionamento da prática com vistas à realização de ações intersetoriais de promoção de saúde e qualidade de vida.

Quanto à promoção de saúde e formação de agentes multiplicadores, faz-se necessário ainda aprofundar a discussão sobre os conceitos, e principalmente os caminhos com vistas à superação de uma prática impositiva e coercitiva para outra mais dialógica, reflexiva e transformadora.

Compreendemos que as mudanças na formação e prática dos profissionais são um processo que demanda investimentos institucionais em educação permanente, mas também na organização e na problematização do processo de trabalho.

Conforme apresentado nos Cadernos de Atenção Básica sobre o Programa de Saúde na Escola, ${ }^{39}$ os setores de educação e de saúde possuem muitas afinidades no campo das políticas públicas, por serem baseados na universalização de direitos fundamentais, e com isso favorecem maior proximidade com os cidadãos nos diferentes territórios. A escola, assim como a rede de saúde, desempenha papel fundamental na formação e atuação das pessoas em todos os âmbitos da vida social, podendo contribuir para a percepção e construção da cidadania e no acesso às políticas públicas. Desse modo, são espaços privilegiados para ações de promoção da saúde.

\section{Referências}

1. Brasil. Ministério da Saúde. Política nacional de promoção da saúde. Brasília: Ministério da Saúde; 2006. $60 \mathrm{p}$.

2. Queiroz MV, Jorge MS. Estratégias de educação em saúde e a qualidade do cuidar e ensinar em pediatria: a interação, o vínculo e a confiança no discurso dos profissionais. Interface - Comunic. Saúde, Educ. 2006; 19(10):117-30.

3. Buss PM. Promoção da saúde e qualidade de vida. Ciência \& Saúde Coletiva. 2000; 5(1):163-177.

4. Castro IRR, Souza TSN. Formação de multiplicadores para a promoção da alimentação saudável: Projeto Culinária, Saúde e Prazer. In: Diez-Garcia RW, Cervato-Mancuso AM. Mudanças alimentares e educação Nutricional. Rio de Janeiro: Guanabara Koogan; 2011. p. 231-244.

5. Coelho MT, Almeida Filho N. Conceitos de saúde em discursos contemporâneos de referência científica. História, Ciências, Saúde 2002; 9(2):315-33.

6. Canguillhem G. O normal e o patológico. Rio de Janeiro: Forense Universitária; 2002.

7. Brito J, Athayde M. Trabalho, educação e saúde: o ponto de vista enigmático da atividade. Trabalho, Educação e Saúde 2003; 1(2): 63-89.

8. Carlini-Cotrim B. Potencialidades da técnica qualitativa grupo focal em investigações sobre abuso de substâncias. Rev. Saúde Pública 1996; 3(30):285-293.

9. Victora, CG, Knauth DR, Hassen MNA. Pesquisa qualitativa em saúde: uma introdução ao tema. Porto Alegre: Tomo Editorial; 2000. 
10. Minayo, MCS. Pesquisa social: teoria, método e criatividade. $12^{\text {a }}$ ed. Petrópolis: Vozes; 1999.

11. Bardin L. Análise de conteúdo. Lisboa: Edições 70; 1979.

12. Gomes R, Souza ER, Minayo MCS, Malaquias JV, Silva CFR. Processamento, análise e interpretação de dados: o desafio da triangulação. In: Minayo MCS. Organizadora. Avaliação por triangulação de métodos: abordagem de programas sociais. Rio de Janeiro: Editora Fiocruz; 2005.

13. Minayo MCS. O desafio do conhecimento: pesquisa qualitativa em saúde. 12ª ed. São Paulo: Hucitec; 2010.

14. VIII Conferência Nacional de Saúde. Relatório final. In: Minayo MCS. organizadora. A Saúde em estado de choque. Rio de Janeiro: Espaço e Tempo/FASE; 1986. p. 117-128.

15. Victora CG, Barreto ML, Leal MC, Monteiro CA, Schmidt MI, Paim J, et al. Condições de saúde e inovações nas políticas de saúde no Brasil: o caminho a percorrer. The Lancet 2011; (6):90-102.

16. Organização Mundial de Saúde. Relatório mundial sobre violência e saúde. Brasília: OMS/OPAS; 2002.

17. Instituto Brasileiro de Geografia e Estatística. Pesquisa Nacional por Amostra de Domicílios: um panorama da saúde no Brasil, acesso e utilização dos serviços, condições de saúde e fatores de risco e proteção à saúde. Rio de Janeiro: IBGE; 2008.

18. Trajano, ARC. Impactos da violência urbana no trabalho em saúde: construindo uma cultura de paz e humanização do trabalho no campo da saúde pública. e-Cadernos CES 2008; (2) [Internet]. acesso em: 31 jan. 2013. Disponível in: http://www.ces.uc.pt/e-cadernos/media/documentos/ecadernos2/ ana $\% 20$ rita $\% 20$ castro $\% 20$ trajano.pdf

19. Chor D. Saúde Pública e mudanças de comportamento: uma questão contemporânea. Cad. Saúde Pública 1999; 15(2):423-425.

20. Mendonça CP, Anjos LA. Aspectos das práticas alimentares e da atividade física como determinantes do crescimento do sobrepeso/obesidade no Brasil. Cadernos de Saúde Pública 2004; 20(3):698-709.

21. Nogueira RP. Para uma análise existencial da saúde. Interface - Comunic., Saúde, Educ. 2006; 10(20):333-45.

22. Bucher-Marluschke JSNF. Como passar da teoria á experiência ou da experiência à teoria: uma lição aprendida. In: Reis A, Paz A, organizadores. Caderno de educação popular e saúde. Brasília: Ministério da Saúde; 2007, p. 87-90.

23. Vaitsman J. Hierarquia de gênero e iniqüidade em Saúde. Physis - Rev. Saúde Coletiva 1994; 4(1):7-22.

24. Rodrigues MC. Vivências da maternidade tardia, cotidiano e qualidade de vida: a perceptiva feminina. [Dissertação]. Viçosa: Universidade Federal de Viçosa; 2008.

25. Neves MA, Pedrosa CM. Gênero, flexibilidade e precarização: o trabalho a domicilio na indústria de confecções. Sociedade e Estado 2007; 22(1):11-34.

26. Gehlen VRF, Raimundo VJ, Vasconcelos RC, Alencar MMCM. O trabalho precário e a saúde precarizada da mulher: uma abordagem sobre as condições das trabalhadoras nas unidades domésticas de produção de confecções de vestuário e acessórios em Toritama - PE. Rede de Estudos do Trabalho 2011; (9):52-76. 
27. Pinheiro R, Guizardi FL. Quando a dádiva se transforma em saúde: algumas reflexões sobre a integralidade e o cuidado nas relações entre sociedade e estado. In: Pinheiro R, Mattos RA, organizadores. Cuidado: as fronteiras da integralidade. Rio de Janeiro: Abrasco; 2004.

28. Pires MRGM. Politicidade do cuidado como referência emancipatória para a gestão de políticas de saúde: conhecer para cuidar melhor, cuidar para confrontar, cuidar para emancipar [Tese]. Brasília: Universidade de Brasília; 2004.

29. Smeke ELM, Oliveira NLS. Educação em saúde e concepções de sujeito. In: Vasconcelos EM, organizador. A saúde nas palavras e nos gestos: reflexões da rede popular e saúde. São Paulo: Hucitec; 2001.

30. Vasconcelos EM, organizador. A saúde nas palavras e nos gestos: reflexões da rede popular e saúde. São Paulo: Hucitec; 2001.

31. Gazzinelli MF, Gazzinelli A, Reis DC, Penna CMM. Educação em saúde: conhecimentos, representações sociais e experiências da doença. Cad. Saúde Pública 2005; 21(1):200-206.

32. Stotz E. enfoques sobre educação popular e saúde. In: Valla VV, Stotz EM. participação popular, educação e saúde: teoria e prática. Rio de Janeiro: Relume-Dumará; 1993. p. 11-22.

33. Brasil. Ministério da Educação. Parâmetros Curriculares Nacionais: introdução aos parâmetros curriculares nacionais. v. 9. Brasília: MEC/SEF; 1997.126 p.

34. Maldonado LA, Castro IRR, Azevedo AMF, Lima EFP, Souza LP, Freire MC, et al. Avaliação do projeto "com gosto de saúde": uma iniciativa de promoção da saúde por meio da educação nutricional em escolas. Saúde em Foco - Informe Epidemiológico em Saúde Coletiva 2002; 23:105-117.

35. Vasconcelos, EM. Educação popular nos Serviços de Saúde. São Paulo: Hucitec; 1999.

36. Souza TSN, Fonseca ABC. Educação em saúde e alimentação na escola: saberes e práticas de profissionais de saúde e de educação. Trab. Educ. Saúde, Rio de Janeiro, 2013 (no prelo).

37. Silva JP, Rotenberg S, Vianna EC. Concepção de educação em saúde na ótica dos profissionais de saúde que atuam em grupos educativos. Cad. Saúde Coletiva 2004; 12(2):119-136.

38. Westphal MF. O movimento cidades/municípios saudáveis: um compromisso com a qualidade de vida. Ciênc. Saúde Coletiva 2000; 1(5):39-51

39. Brasil. Ministério da Saúde. Saúde na escola. Brasília: Ministério da Saúde; 2009. 96 p.

Recebido: $13 / 3 / 2014$

Aprovado: $24 / 4 / 2014$ 
